\title{
Angiogenesis in Tissue Engineering: Breathing Life into Constructed Tissue Substitutes
}

\author{
MATTHIAS W. LASCHKE, M.D., ${ }^{1}$ YVES HARDER, M.D., ${ }^{1,2}$ MICHAELA AMON, ${ }^{1}$ \\ IVAN MARTIN, Ph.D., ${ }^{3}$ JIAN FARHADI, M.D., ${ }^{4}$ ANDREJ RING, M.D., ${ }^{5}$ NESTOR \\ TORIO-PADRON, M.D. ${ }^{6}$ RENÉ SCHRAMM, M.D., Ph.D., ${ }^{1}$ MARTIN RÜCKER, M.D., ${ }^{7}$ DOMINIC \\ JUNKER, ${ }^{1}$ JÖRG M. HÄUFEL, ${ }^{1}$ CARLOS CARVALHO ${ }^{8}$ MICHAEL HEBERER, M.D., ${ }^{3}$ GÜNTER \\ GERMANN, M.D., ${ }^{9}$ BRIGITTE VOLLMAR, M.D., ${ }^{10}$ and MICHAEL D. MENGER, M.D. ${ }^{1}$
}

\begin{abstract}
Long-term function of three-dimensional (3D) tissue constructs depends on adequate vascularization after implantation. Accordingly, research in tissue engineering has focused on the analysis of angiogenesis. For this purpose, 2 sophisticated in vivo models (the chorioallantoic membrane and the dorsal skinfold chamber) have recently been introduced in tissue engineering research, allowing a more detailed analysis of angiogenic dysfunction and engraftment failure. To achieve vascularization of tissue constructs, several approaches are currently under investigation. These include the modification of biomaterial properties of scaffolds and the stimulation of blood vessel development and maturation by different growth factors using slow-release devices through pre-encapsulated microspheres. Moreover, new microvascular networks in tissue substitutes can be engineered by using endothelial cells and stem cells or by creating arteriovenous shunt loops. Nonetheless, the currently used techniques are not sufficient to induce the rapid vascularization necessary for an adequate cellular oxygen supply. Thus, future directions of research should focus on the creation of microvascular networks within 3D tissue constructs in vitro before implantation or by co-stimulation of angiogenesis and parenchymal cell proliferation to engineer the vascularized tissue substitute in situ.
\end{abstract}

\section{INTRODUCTION}

$\mathbf{T}$ ISSUE ENGINEERING IS AN EMERGING FIELD OF SCIENCE that the National Science Foundation first defined in 1987 as "an interdisciplinary field that applies the principles of engineering and the life sciences towards the development of biological substitutes that restore, maintain or improve tissue function." ${ }^{11}$ Because the loss or failure of tissue or an organ is one of the most frequent and expensive problems in human health care today, it is expected that the development of methods to regenerate human tissue or to reconstruct entire organs using tissue engineering will have an important influence on various medical specialties in the future.

\footnotetext{
${ }^{1}$ Institute for Clinical and Experimental Surgery, University of Saarland, Homburg, Germany.

${ }^{2}$ Department of Plastic and Reconstructive Surgery, University of Berne, Switzerland.

${ }^{3}$ Institute for Surgical Research, University of Basel, Switzerland.

${ }^{4}$ Department of Plastic and Reconstructive Surgery, University of Basel, Switzerland.

${ }^{5}$ Department of Plastic and Hand Surgery/Burn Center, University of Bochum, Germany.

${ }^{6}$ Department of Plastic and Hand Surgery, University of Freiburg, Germany.

${ }^{7}$ Department of Oral and Maxillofacial Surgery, Medical University of Hannover, Germany.

${ }^{8}$ FMF Freiburger Materialforschungszentrum, Freiburg, Germany.

${ }^{9}$ Department of Plastic, Reconstructive and Hand Surgery/Burn Center, University of Heidelberg, Ludwigshafen, Germany.

${ }^{10}$ Department of Experimental Surgery, University of Rostock, Schillingallee 70, Rostock, Germany.
} 
Plastic and reconstructive surgery would benefit in particular from tissue engineering to the extent that the application of artificially engineered tissue may be completely substituted for current clinical techniques such as flap surgery for the treatment of extensive skin defects and implantation of foreign materials for breast reconstruction. First steps toward those novel strategies have already been taken. Engineered skin and cartilage have recently been introduced for clinical use., ${ }^{2,3}$ Several other potential tissue types for substitutive treatment are currently under investigation, including liver,,${ }^{4,5}$ bone, ${ }^{6}$ muscle,${ }^{7}$ adipose,${ }^{8,9}$ and nervous ${ }^{10}$ tissues.

Engineered cartilage is a relatively simple tissue, because cartilage is avascular and has a low metabolic demand. In contrast, the engineering of more complex tissues consisting of large 3D structures remains a critical challenge. Because the amount of oxygen required for cell survival is limited to a diffusion distance of approximately 150 to $200 \mu \mathrm{m}$ from the supplying blood vessel, ${ }^{11,12}$ longterm survival and function of such 3-dimensionally constructed tissues depend on rapid development of new blood vessels, which provide nutrients and oxygen to the cells not only of the margin but also of the center of the tissue grafts. In fact, the growth of a new microvascular system remains one of the major limitations in the successful introduction of tissue engineering products to clinical practice. Accordingly, the focus of research in tissue engineering has changed toward the understanding of angiogenesis and new blood vessel formation.

Angiogenesis is defined as the formation of new capillaries from pre-existing blood vessels and represents a complex dynamic process characterized by a coordinated sequence of humoral and cellular interactions. ${ }^{13,14}$ Upon angiogenic stimulation, vascular endothelial cells are activated and begin to degrade their surrounding basement membrane by the expression and release of matrix metalloproteinases as indicated by vasodilatation. Then the endothelial cells migrate into the interstitium, resulting in the formation of capillary buds and sprouts. Endothelial cells behind the migrating endothelium of the sprouts proliferate so that the newly developing blood vessel elongates. The stabilization of the new vessel wall requires the recruitment of other cell types, including smooth muscle cells, pericytes, and fibroblasts, as well as the production of extracellular matrix compounds. The interaction of distinct soluble factors such as cytokines and growth factors tightly regulates all these steps. ${ }^{15}$

\section{IN VIVO MODELS TO STUDY ANGIOGENESIS IN TISSUE ENGINEERING PRODUCTS}

To improve current techniques and to develop new strategies for optimal vascularization of implanted tissue constructs, sophisticated experimental models are required that allow for a detailed analysis of blood vessel ingrowth in engineered tissue constructs in vivo. Previous studies have analyzed the process of angiogenesis primarily using in vitro cell culture experiments and histological examinations of formalin-fixed tissue. Recently, however, 2 commonly used in vivo models to study angiogenesis, the chorioallantoic membrane (CAM) assay and the dorsal skinfold chamber, have been introduced in the field of tissue engineering.

\section{The CAM assay}

The chicken embryo CAM is an extraembryonic membrane that serves as a transient gas exchange surface, similar to the lung. The allantois of the chicken embryo first appears at day 3 of incubation and rapidly grows until day 10 . The adjacent mesodermal layers of the chorion and the allantois fuse to form the CAM, which is characterized by a dense microvascular network (Fig. 1) ${ }^{16,17}$ During the first days of incubation, undifferentiated blood vessels are scattered in the mesoderm of the CAM. These vessels grow rapidly until day 8 , when some differentiate into capillaries. The ability of the CAM to support the ingrowth of blood vessels in implanted tissue substitutes depends on the day of implantation, because vascularization increases with expansion and differentiation of the CAM parallel to the development of the embryo. Between incubation days 9 and 12, the CAM reaches its maximum vascularization potential. Afterwards, blood vessels of the CAM begin to regress until incubation day 21, when the chick hatches. Thus, implantation studies using the CAM model can be performed between incubation days 5 and 15 (the first 10 days after implantation).

Embryologists originally developed the CAM assay to study the developmental potential of embryonic tissue grafts. During the last decades, this in vivo model has successfully been used to investigate basic mechanisms of angiogenesis

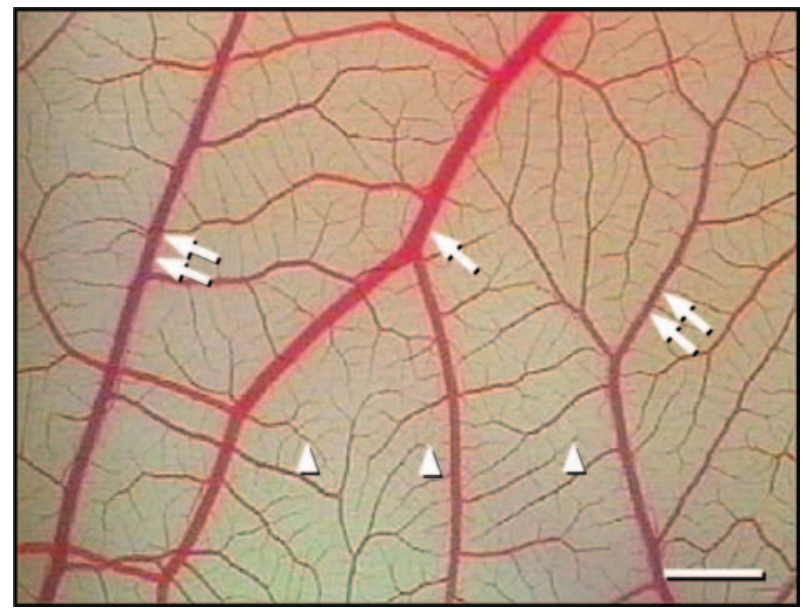

FIG. 1. High-resolution, epi-illumination in vivo microscopy, visualizing the microvascular network of the chorioallantoic membrane at day 14 of incubation, consisting of supplying arterioles (arrow), nutritive capillaries (arrow heads), and draining venules (double arrows). Scale bar: $2.2 \mathrm{~mm}$. Color images available online at www.liebertpub.com/ten. 
such as migration, proliferation, and differentiation of endothelial cells, ${ }^{18-20}$ changes of the extracellular matrix, ${ }^{21,22}$ and the effect of growth factors and angiogenesis inhibitors on blood vessel development. ${ }^{23-25}$ Moreover, the CAM is a suitable model for the assessment of the angiogenic potential of transplanted benign ${ }^{26}$ and malignant tissue, ${ }^{27,28}$ whereby xenografts from mammalian species can be implanted into the CAM without rejection. This is because the early chicken embryo lacks a complete immune system. Further advantages of this model include easy preparation of the CAM vascular network, low costs, and less-severe restrictions on its use than with mammal models.

Two-dimensionally designed matrix constructs and mesh networks may be positioned directly onto the CAM to perform high-resolution imaging of the vascularization process (Fig. 2). Engineered constructs with an increased 3D extension, however, cannot be studied using this approach. Therefore, Borges et al. have modified the original CAM assay to a cylinder model. ${ }^{29,30}$ For this purpose, fertilized chicken eggs were incubated at $37.8^{\circ} \mathrm{C}$ for 3 days. Then, the eggs were prepared for implantation of the tissue construct by opening the eggshell in a circular area and removing enough albumen to minimize adhesion of the shell membrane. After 5 days of reincubation, cultivated human subcutaneous preadipocytes, which were integrated into a matrix of fibrin glue, were implanted in a specially designed plastic cylinder filled with cell medium and placed through the prepared observation window onto the surface of the CAM. In this way, it was possible to investigate the early steps of vascularization of the constructs for up to 8 days post-implantation using light microscopic and histological techniques. ${ }^{29}$ In a second set of experiments, adult human dermal microvascular endothelial cell spheroids and preadipocytes were combined in a fibrin matrix and implanted into the CAM. ${ }^{30}$ This resulted in the formation of a new capillary network within the tissue construct, consisting of human endothelial cells, which connected to the CAM vessel system. This finding demonstrates that the cotransplantation of endothelial cell spheroids with mesenchymal cells might be a promising new approach to engineering adequately vascularized tissue constructs without applying exogenous angiogenic growth factors.

In addition to the restriction in use to a period of approximately 10 days, there are some limitations on the application of the CAM assay. Native epi-illumination microscopy is adequate to study blood vessels with a size of more than $10 \mu \mathrm{m}$, whereas smaller blood vessels (capillaries after maturation) are more difficult to visualize. This drawback can be overcome using intravascular application of a highmolecular-weight fluorescent marker, which, however, requires sophisticated manual skills. Furthermore, the initial lack of an immune system may be advantageous for the study of xenografts but does not allow the assessment of the material biocompatibility. Finally, using the CAM assay,
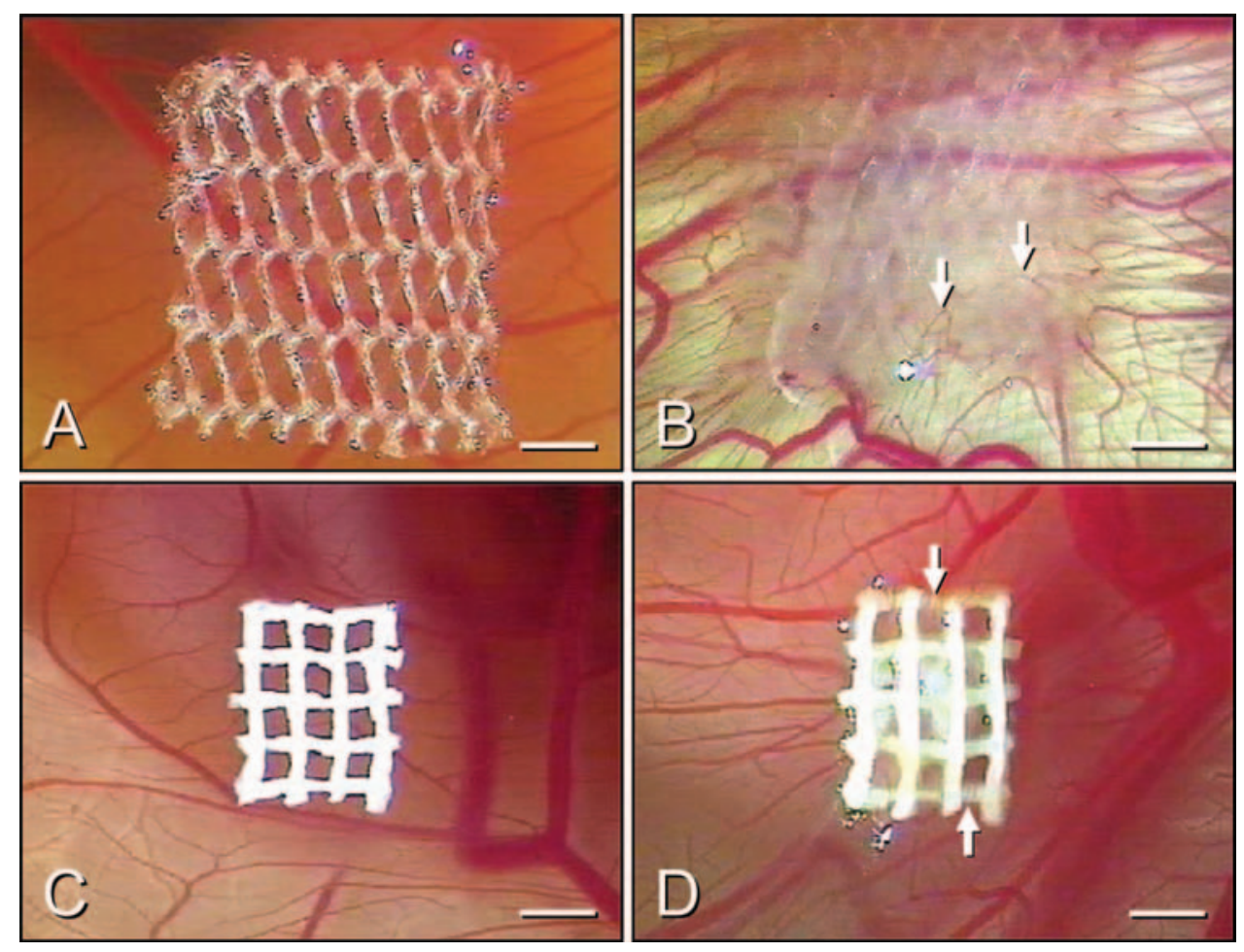

FIG. 2. The chorioallantoic membrane model allows the vascularization and engraftment of various biomaterials to be studied. Implantation of a polyglactin 910 mesh $(\mathbf{A})$ and a hydrogel scaffold $(\mathbf{C})$ at day 7 of incubation induces angiogenesis, resulting in adequate ingrowth of newly formed blood vessels (arrows) until day 14 of incubation (B, D). Scale bars: $\mathbf{A}, \mathbf{B}=0.9 \mathrm{~mm} ; \mathbf{C}, \mathbf{D}=1.4 \mathrm{~mm}$. Color images available online at www.liebertpub.com/ten. 
one should be aware that it consists of embryonal tissue, which itself is characterized by a growth factor profile different from that of adult tissue.

Overall, however, we feel that the CAM must be considered to be a suitable screening assay that allows for the study of cell viability, proliferation, and differentiation within implanted tissue constructs during the early steps of vascularization (the first 10 days after implantation). The model enables the investigation of the effect of angiogenic factors and gene therapy on transplanted cells and of the distinct vascularization properties of different biomaterials used for the engineering of tissue constructs.

\section{The dorsal skinfold chamber}

Algire first introduced the dorsal skinfold chamber in mice in $1943 .{ }^{31}$ During the last 3 decades, it has been modified and adapted for the use in rats, ${ }^{32}$ immunocompetent mice, ${ }^{33}$ nude and severe combined immuno-deficient mice, ${ }^{34,35}$ and hamsters. ${ }^{36}$

For surgical preparation, the back of the anesthetized animal is shaved and depilated. Two symmetrical titanium frames are implanted on the extended dorsal skinfold so that they sandwich the double layer of skin. Subsequently, 1 layer of skin is completely removed in a circular area of approximately $15 \mathrm{~mm}$ in diameter, and the remaining layers (consisting of striated skin muscle, subcutaneous tissue, and skin) are covered with a removable coverslip incorporated into the observation window of one of the titanium frames. After the preparation, the animals are allowed to recover for at least $48 \mathrm{~h}$ to exclude changes of the microcirculation due to anesthesia and surgical trauma.

The major advantage of the dorsal skinfold preparation is that the microcirculation can be analyzed through the observation window repetitively in unanesthetized animals over a period of 3 to 4 weeks (Fig. 3). ${ }^{37}$ Furthermore, the chamber model is ideal for transplantation and implantation experiments, because the cover glass of the observation window can temporarily be removed. The skinfold chamber model has been used to study angiogenesis within various physiological tissues $^{38-42}$ and malignant tumors, ${ }^{43,44}$ as well as biomaterials such as synthetic and biosynthetic vascular grafts ${ }^{45-47}$ and metallic implants. ${ }^{48-50}$ Using this model, the quantification of the angiogenic process is possible using the combination of epi-illumination multi-fluorescence microscopy and computer-assisted off-line analysis techniques (Fig. 4-6). Moreover, cellular and molecular aspects can be assessed, including leukocyte and platelet adhesion, macrophage activation, mast cell degranulation, vascular endothelial leakage, and apoptotic and necrotic cell death.

There are also some limitations in the use of the dorsal skinfold chamber for studying angiogenesis in tissue engineering constructs. The size of the construct should not exceed $5 \mathrm{~mm}$ in diameter (width and length) to adequately fit within the 11-mm-sized chamber. Moreover, the height of the construct should be limited to $1 \mathrm{~mm}$ to ensure ade-
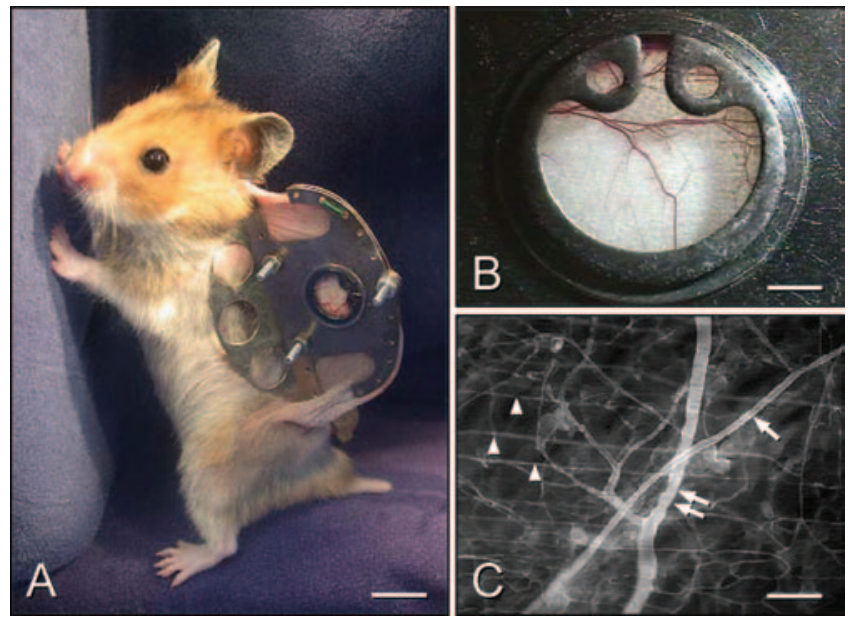

FIG. 3. (A) Syrian golden hamster equipped with a dorsal skinfold chamber (weight $\sim 4 \mathrm{~g}$ ). (B) Overview of the observation window after the implantation of the chamber into the dorsal skinfold. Large microvessels (arterioles and venules of the striated muscle and subcutaneous tissue) can be identified without the use of high-resolution intravital fluorescence microscopy. (C) Intravital fluorescence microscopy of the micro-angioarchitecture of the dorsal skinfold chamber consisting of arterioles (arrow), parallelly arranged muscle capillaries (arrowheads), and postcapillary and collecting venules (double arrows). Blue light epiillumination with intravascular plasma contrast enhancement by $5 \%$ fluorescein isothiocyanate-labeled dextran 150,000 i.v. Scale bars: $\mathbf{A}=12.5 \mathrm{~mm} ; \mathbf{B}=2.5 \mathrm{~mm} ; \mathbf{C}=105 \mu \mathrm{m}$. Color images available online at www.liebertpub.com/ten.

quate closure of the chamber tissue by the cover glass. Despite these limitations, we feel that the dorsal skinfold chamber model is an ideal tool for the long-term in vivo study of blood vessel growth and remodeling in porous biomedical materials used in the field of tissue engineering.

Druecke et al. used the dorsal skinfold chamber of mice to study neovascularization and biocompatibility of acellular poly(ether ester) block-copolymer scaffolds of different pore sizes. ${ }^{51}$ This type of biomaterial can be easily tailored, is biodegradable, and has been proven to support ingrowth of different tissues. After implantation of the scaffolds into the dorsal skinfold chambers, vascularization of the scaffolds was analyzed over 20 days. The results of the study showed that pore size influences vessel ingrowth into poly(ether ester) block-polymer scaffolds, which was most pronounced in the scaffolds with the largest pores. This corresponds with what has been reported from new vessel formation in synthetic vascular graft materials ${ }^{45}$ and underlines the importance of the biomaterial properties for the vascularization process of implanted tissue constructs.

\section{ANGIOGENESIS AND VASCULARIZATION OF TISSUE ENGINEERING CONSTRUCTS}

The angiogenic process is of particular interest if a new structurally integrated tissue is generated from autologous 

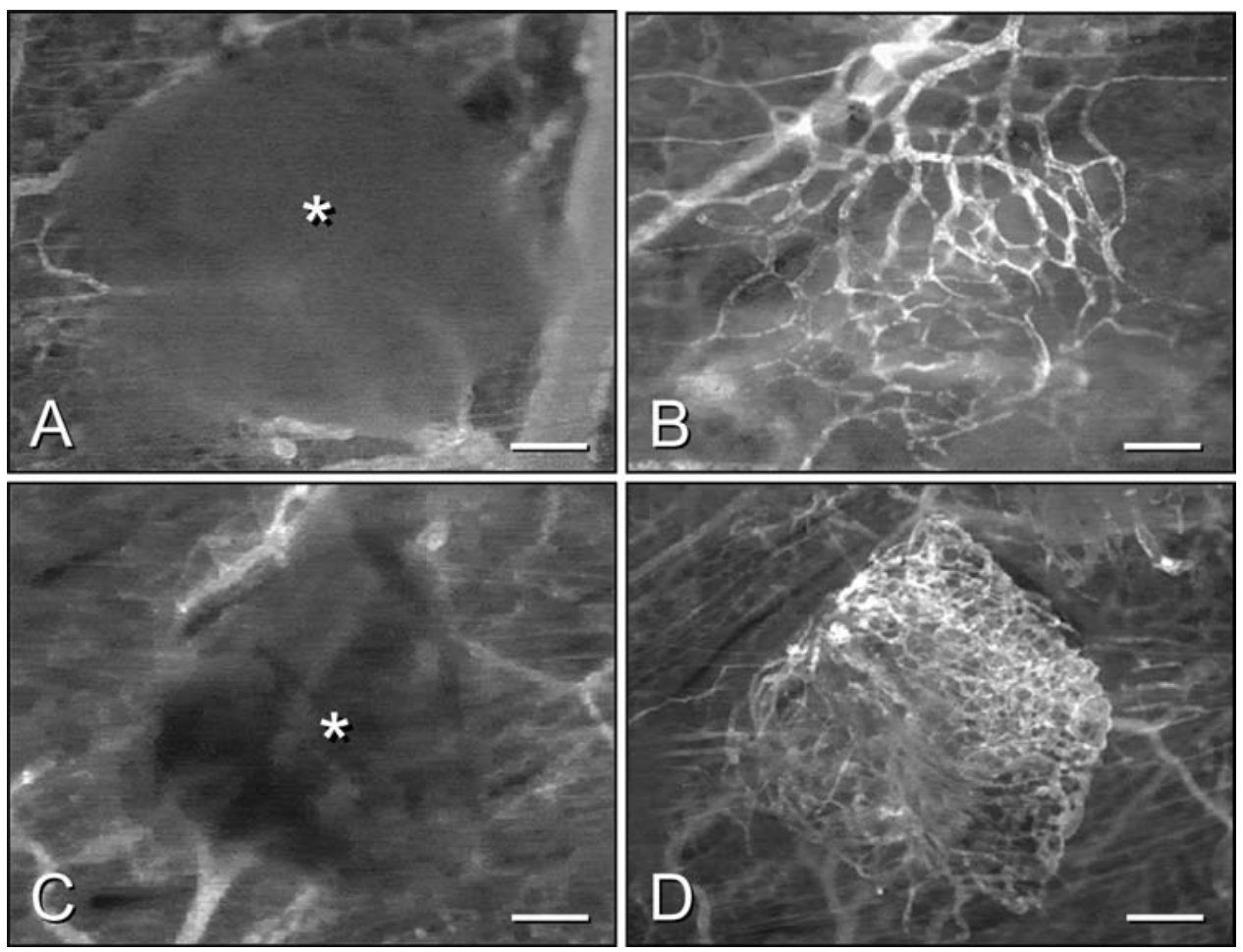

FIG. 4. Intravital fluorescence microscopy of an isolated ovarian follicle (A, asterisk) and an endometrial tissue fragment (C, asterisk) directly after transplantation into the dorsal skinfold chamber of a Syrian golden hamster. After 10 days, the grafts are completely vascularized exhibiting a dense, glomerular-like network of newly formed microvessels (B, D). Scale bars: $\mathbf{A}, \mathbf{B}=105 \mu \mathrm{m} ; \mathbf{C}$, $\mathbf{D}=170 \mu \mathrm{m}$.

cultured cells. For this purpose, a small tissue sample is taken from the patient, and the cells are then isolated and expanded in culture. Subsequently, these cells are transferred into a 3D scaffold, which serves as a template for new tissue formation. Finally, this tissue construct can be implanted back into the patient, with the surgical procedure inducing an inflammatory wound-healing response. This, together with the hypoxia of the cells seeded onto the implant, stimulates the endogenous release of angiogenic growth factors, which themselves trigger the ingrowth of new blood vessels from the surrounding host tissue.

However, although blood vessel ingrowth is often noted in implanted tissue constructs over time, the vascularization is too slow or too limited to provide adequate nutrient and oxygen transport to the transplanted cells. To solve this problem, several approaches are currently under investigation.

\section{The search for the ideal scaffold}

Scaffolds provide a 3D framework for cells to attach to and on which to proliferate that can be implanted into a tissue defect site. In general, 2 main types of scaffolds can be differentiated: synthetically derived polymer scaffolds ${ }^{52}$ and naturally occurring scaffolds. ${ }^{53}$

Synthetically derived polymer scaffolds should be biocompatible and biodegradable and should ensure an optimal interaction with endothelial cells to promote angiogenesis. To develop scaffolds that fulfill these properties, it is of great importance to investigate how different biomaterials modulate endothelial cell function. For this purpose, a variety of endothelial cell culture systems have been established during recent years. They allow for the evaluation of new biomaterials in terms of endothelial cell attachment,${ }^{54}$ cytotoxicity, ${ }^{55}$ growth,${ }^{56}$ angiogenesis, ${ }^{57}$ and gene regulation. ${ }^{56}$ Additionally, co-culture systems can be used to study blood vessel development in tissue constructs on a higher level of cellular organization, considering the interaction between endothelial cells and other cell types. ${ }^{58,59}$

In addition to the cellular interaction with biomaterials, the architecture of the scaffold seems to play an important role in adequate vascularization. Pinney et al. reported that the 3D structure of a scaffold in itself can change the angiogenic activity of incorporated cells. ${ }^{60}$ When culturing fibroblasts on a lactate-glycolate copolymer scaffold to form a dermal-equivalent tissue, they observed that the cellular content of vascular endothelial growth factor (VEGF) messenger ribonucleic acid in these 3D cultures was 22 times greater than that in the same fibroblasts grown as monolayers. In addition, the pore size of the scaffolds has been shown to be a critical determinant of blood vessel ingrowth, ${ }^{51}$ which is significantly faster in pores with a size greater than $250 \mu \mathrm{m}$ than in those less than $250 \mu \mathrm{m}$. 


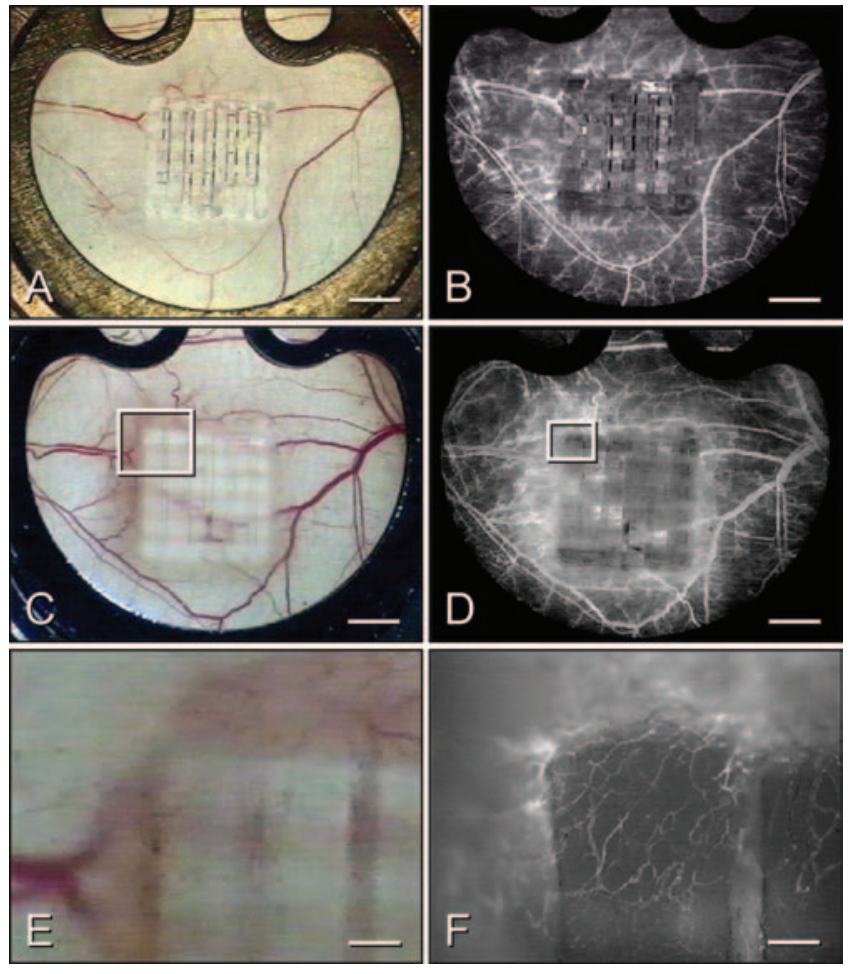

FIG. 5. Overview of the observation window of a mouse dorsal skinfold chamber directly after implantation of a poly(lactide-coglycolide) (PLGA) scaffold (A, B) and 10 days later (C, D). Higher magnification of selected regions of interest in the border zone of the scaffold (C, D: white frame) at day 10 after implantation demonstrates the formation of new blood vessels growing into the scaffold biomaterial $(\mathbf{E}, \mathbf{F})$. The visualization of the microcirculation is much more detailed using high-resolution intravital fluorescence microscopy with intravascular plasma contrast enhancement by $5 \%$ fluorescein isothiocyanate-labeled dextran 150,000 i.v. (B, D, F) than corresponding images made under a stereo-microscope (A, C, E). Scale bars: $\mathbf{A}-\mathbf{D}=1.4 \mathrm{~mm}$; $\mathbf{E}=240 \mu \mathrm{m} ; \mathbf{F}=105 \mu \mathrm{m}$. Color images available online at www .liebertpub.com/ten.

Finally, molecular deteriorations that are induced during the incorporation process of the implant might influence the ingrowth of blood vessels into scaffolds. This may explain why currently used biomaterials partly fail to vascularize, independent of their material properties. Fibronectin, for example, is the only mammalian adhesion protein that binds and activates $\alpha_{5} \beta_{1}$-integrins, which are known to exert proangiogenic actions, although Vogel and Baneyx ${ }^{61}$ who investigated the role of this adhesion protein in scaffold vascularization, could not demonstrate an acceleration or improvement of implant vascularization but documented an inhibitory action on the process of new vessel formation. This inhibition was interpreted as the result of excessive tension generated by cells in contact with implanted biomaterials, which may have changed the molecular structure of fibronectin fibrils, deteriorating their capability to bind and activate $\alpha_{5} \beta_{1}$-integrins.
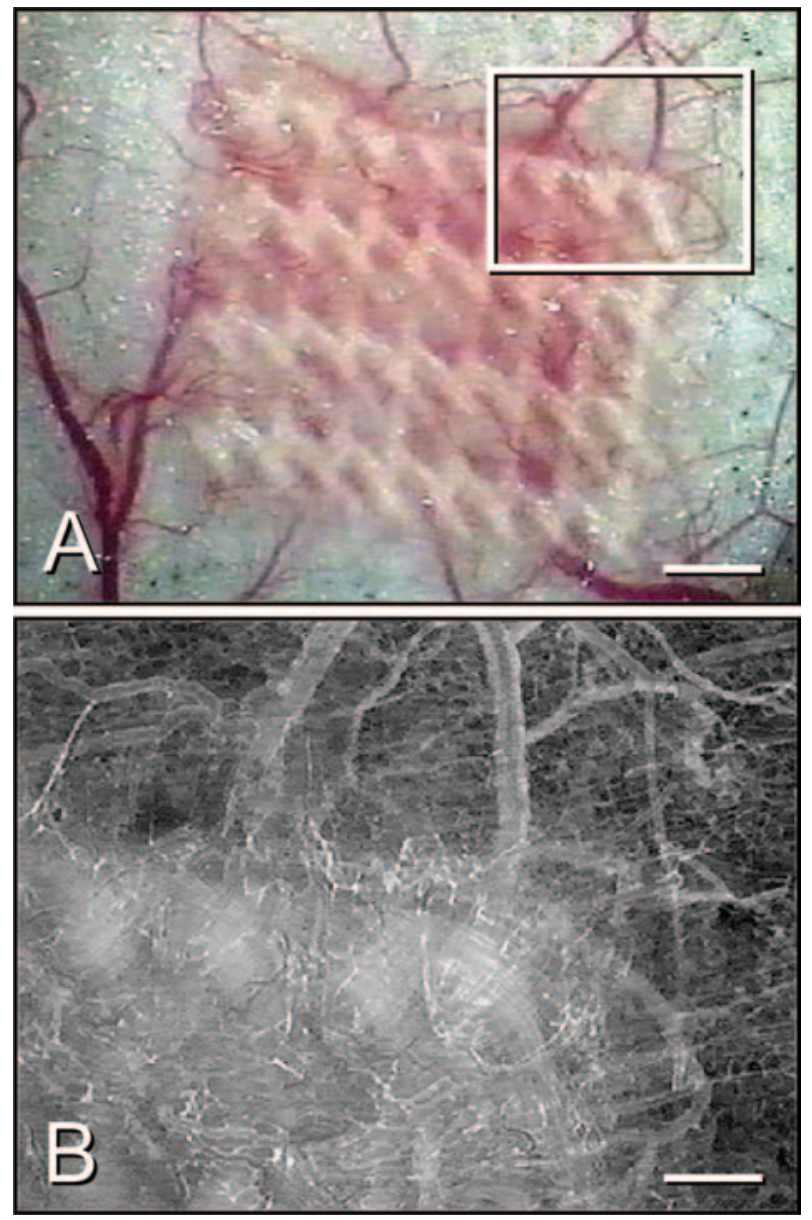

FIG. 6. Epi-illumination in vivo microscopy of a polyglactin 910 mesh 14 days after implantation into the dorsal skinfold chamber of a Syrian golden hamster (A). Intravital fluorescence microscopy with intravascular plasma contrast enhancement by $5 \%$ fluorescein isothiocyanate-labeled dextran 150,000 i.v. of the border zone of the mesh (A: white frame) shows the formation of a dense network of newly formed microvessels entwining the synthetic mesh fibers $(\mathbf{B})$. Scale bars: $\mathbf{A}=875 \mu \mathrm{m} ; \mathbf{B}=380 \mu \mathrm{m}$. Color images available online at www.liebertpub.com/ten.

In addition to synthetically derived polymer scaffolds, naturally occurring scaffolds composed of extracellular matrix proteins offer promising alternatives for tissue repair and regeneration. Important examples are small intestinal submucosa, acellular dermis, cadaveric fascia, the bladder acellular matrix graft, and the amniotic membrane. ${ }^{53}$ These types of scaffolds have been shown to promote rapid interaction with the surrounding host tissue, to induce the deposition of cells and additional extracellular matrix, and to accelerate the process of angiogenesis. These naturally occurring scaffolds can be processed so that they retain growth factors, ${ }^{62}$ glycosaminoglycans, ${ }^{63}$ and structural elements such as fibronectin, elastin, and collagen, ${ }^{64,65}$ which are important regulatory factors of angiogenesis. For example, Pieper et al. ${ }^{66}$ demonstrated that the attachment of glycosaminoglycans to collagen matrices preserves porous 
matrix integrity and promotes blood vessel ingrowth. In another study, elastic fibers of an extracellular matrix scaffold were shown to act as "microguides" for endothelial cell and pericyte migration during capillary sprouting. ${ }^{67}$ However, many questions remain to be answered until naturally occurring scaffolds can be used for clinically relevant tissue engineering, including the immunologic response of the host to such implants and the methods to modify their mechanical and physical properties. ${ }^{68}$ Thus, the ideal scaffold, which promotes angiogenesis of engineered tissue sufficiently, has not been determined.

\section{Stimulation of angiogenesis by growth factors}

Growth factors play the central regulatory role in the process of angiogenesis. In recent decades, many of these factors were identified and are now available in recombinant forms to support engraftment of tissue engineering products. These include VEGF, platelet-derived growth factor (PDGF), and different fibroblast growth factors (FGF-1 and FGF-2). ${ }^{69}$

The systemic application of these factors might accelerate the ingrowth of blood vessels into implanted tissue constructs. However, this strategy is limited, because the inherent instability of many growth factors requires high levels of protein for a measurable effect in vivo, and the risk of blood vessel development at distant sites of the body remains uncontrolled. ${ }^{70}$

A better alternative seems to be the incorporation of growth factors into the scaffold biomaterial, which guarantees localized and sustained delivery. This principle has already been shown to be successful in a rabbit ear ulcer model, in which the delivery of FGF-1 through biodegradable fibrin or collagen scaffolds resulted in an enhanced healing process of full-thickness skin defects, as indicated by increased angiogenesis and enhanced epithelialization. ${ }^{71,72}$ In general, there are 2 possibilities to incorporate growth factors into synthetic scaffolds. It can be done by simply mixing the growth factor with polymer particles before processing the polymer into a porous scaffold, resulting in a rapid release of the growth factor within days to weeks. ${ }^{73}$ The second approach involves the pre-encapsulation of growth factors in microspheres, which are then incorporated into the scaffold, guaranteeing growth factor release over a longer time span. ${ }^{74,75}$ Recently, Richardson et al. combined these 2 approaches to establish a new polymer system that allows for the delivery of 2 or more growth factors with distinct kinetics. ${ }^{76}$ By using this system, they could demonstrate that dual delivery of VEGF and PDGF, each with distinct kinetics, results in the rapid formation of a mature vascular network inside polymer scaffolds that had been implanted into the subcutaneous tissue of rats.

Local release of growth factors may also be achieved by transplanting fragmented tissue such as omentum. The omentum contains a large number of microvascular endothelial cells and is composed mainly of adipocytes that produce an enormously high level of VEGF. ${ }^{77} \mathrm{Co}-$ transplantation of fragmented omentum with preadipocytes under the dorsal skin of Wistar rats has been shown to effectively augment soft tissue by increasing VEGF production and capillary growth. ${ }^{77}$

Finally, blood vessel development might be stimulated using gene transfer of angiogenic growth factors to the cells incorporated into the scaffold. ${ }^{78}$ The idea behind this approach is to achieve an in vivo controlled release of the growth factor for a certain period. In the past, the angiogenic therapy of bone tissue regeneration ${ }^{79}$ and ischemic diseases $^{80-82}$ was attempted by applying plasmids carrying growth factor deoxyribonucleic acid. However, at present there is no information about the adverse effects of such gene therapy, and it is impossible to control the level and time period of gene expression. Thus, the controlled release of growth factors on the protein level seems safer and clinically more applicable than the use of gene transfer procedures. ${ }^{83}$

\section{Engineering vascularized tissue in vitro}

A network of newly developed microvessels may be engineered in vitro by seeding scaffolds with endothelial cells. ${ }^{84,85}$ After implantation of those tissue constructs, the endothelial cells should develop interconnections to the blood vessels of the surrounding tissue, resulting in an adequate perfusion of the prefabricated microvascular network. By using this method, the period required for the ingrowth of new blood vessels into the center of the scaffold can be dramatically shortened. However, there remain a considerable number of unsolved problems to realize this theoretical approach. Although different seeding methods for 3D polymeric scaffolds have been established, ${ }^{86-88}$ it is unclear whether they can guarantee a homogeneous distribution of endothelial cells throughout a large tissue construct. Moreover, the seeding of a scaffold with endothelial cells does not necessarily result in the development of new blood vessels in vitro, because this process depends on the coordinated release of a variety of signaling factors such as VEGF and PDGF and involves other cell types, including smooth muscle cells and pericytes, which are normally found under in vivo conditions but not necessarily in vitro. Thus, further research is needed to improve current cell culture and seeding techniques for the development of tissue constructs, which bear their own intrinsic vascular system before implantation and engraftment. Tremblay et al. have most recently reported promising results. ${ }^{89}$ With the use of endothelialized reconstructed skin in which a network of human capillary-like structures was spontaneously formed within the dermis in vitro, they showed successful inosculation of the in vitro constructed microvasculature to host blood vessels in less than 4 days after implantation. ${ }^{89}$

\section{Induction of vascularization by stem cells}

In the near future, the use of autologous stem cell sources will become of major importance for constructing new 
tissues. Several studies have recently reported the successful creation of tissue-engineered vascular grafts with good long-term function by seeding different grafts with bone marrow cells and endothelial progenitor cells. ${ }^{90-92}$

In addition, endothelial progenitor cells from the bone marrow circulate in the bloodstream and are incorporated into the vessel wall. In culture, these cells have been shown to give rise to 3 important blood vessel cell components: endothelial cells, pericytes, and vascular smooth muscle cells. ${ }^{93}$ In vivo, a considerable number of experimental studies could demonstrate that these progenitor cells are capable of inducing angiogenesis and vasculogenesis at sites of critical perfusion and hypoxia, such as myocardial infarction, stroke, and hind-limb ischemia. ${ }^{94}$ Progenitor cell-derived regeneration and repair of ischemic or necrotic tissue are thought to be due to an enhancement of functional re- or neovascularization. ${ }^{95}$ Accordingly, the vesselforming capacity of stem and progenitor cells may also be useful to improve survival and function of constructed tissue substitutes by induction and acceleration of angiogenesis and maturation of newly formed blood vessels. Future research that aims at improving angiogenesis in tissue constructs should thus include the therapeutic use of endothelial progenitor cells.

\section{Engineering vascularized tissue in vivo}

In 1979, Erol and Spira reported a new method to facilitate engraftment in poorly vascularized tissues. ${ }^{96}$ For this purpose, they implanted an arteriovenous shunt loop in the rat groin. After some days, they observed the development of new blood vessels originating from the loop that could support engraftment of an overlying skin graft. Since then, a number of other experimental studies have used an arteriovenous shunt loop as a vascular carrier for prefabricated skin flaps. ${ }^{97-99}$ The principle of this method is the induction of angiogenesis by increased shear stress and wall tension within the loops' vasculature. It is believed that these 2 factors disturb the integrity of endothelial and vascular smooth muscle cells, making them more susceptible to the action of angiogenic growth factors. ${ }^{13}$

Recently, Mian et al. demonstrated that this approach can be used to engineer new connective tissue in vivo. ${ }^{100,101}$ They used a model comprising an arteriovenous shunt loop sandwiched in artificial dermis and placed in a plastic growth chamber. After subcutaneous implantation of this chamber, fibroblast and vascular outgrowth from the arteriovenous shunt resulting in the development of a wellvascularized mass of mature fibrous tissue was observed. With the use of this technique, Dolderer et al. ${ }^{9}$ reported the in vivo generation of large amounts of vascularized adipose tissue. An adipofascial tissue flap and a matrix scaffold were integrated into a growth chamber, which was then implanted into pigs. After 12 weeks, newly formed adipose tissue had grown to up to $60 \%$ of the chamber volume, and when this tissue was transferred to another site in the body, it stayed stable in volume and showed no signs of fibrotic alteration. ${ }^{9}$ Thus, this novel approach of in vivo tissue engineering may represent a first step toward the endogenous production of significant amounts of vascularized adipose tissue for autologous soft tissue replacement.

\section{CONCLUSION AND PERSPECTIVES}

Research on tissue engineering during the last few years has brought evidence that delayed vascularization or lack of vascularization is one of the major obstacles to successfully realizing the clinical use of in vitro engineered tissue and organ substitutes. The design of the scaffold of the tissue construct, including nature and texture of the material, may help to overcome the limitations in new blood vessel ingrowth. A porosity of more than $250 \mu \mathrm{m}$ seems mandatory for adequate vascularization. The ideal nature of the material, however, has yet to be determined. Furthermore, 3 distinct approaches seem to be most promising in improving and accelerating vascularization and thus should be addressed by future research in tissue engineering: (1) the creation of microvascular networks within 3D tissue constructs in vitro with inosculation to the host's vasculature after implantation; (2) the co-stimulation of angiogenesis and parenchymal cell proliferation, for example, with the use of arteriovenous shunt loops, to engineer the vascularized tissue substitute entirely in situ; and (3) the incorporation of progenitor or stem cells, in vivo and in vitro, to accelerate the formation and maturation of new blood vessels. These 3 approaches, which must be further tested in sophisticated in vivo models, may further open the door to successful clinical use of tissue-engineered products in organ replacement.

\section{ACKNOWLEDGMENTS}

We are grateful for the financial support of the Homburg Surgical Research Symposium "Angiogenesis and Microcirculation in Flap Surgery" by Ethicon Products GmbH. This article is based on conclusions drawn at the Homburg Surgical Research Symposium "Angiogenesis and Microcirculation in Flap Surgery," held in November 2004 at the Monastery Hornbach, Germany. All authors contributed by presentation or intensive discussion at the meeting. The article was written by MWL and MDM. All authors reviewed and approved the article.

\section{REFERENCES}

1. Langer, R., and Vacanti, J.P. Tissue engineering. Science 260, 920, 1993.

2. Vacanti, C.A., and Upton, J. Tissue-engineered morphogenesis of cartilage and bone by means of cell transplantation 
using synthetic biodegradable polymer matrices. Clin Plast Surg 21, 445, 1994.

3. Kremer, M., Lang, E., and Berger, A.C. Evaluation of dermalepidermal skin equivalents ('composite-skin') of human keratinocytes in a collagen-glycosaminoglycan matrix (Integra artificial skin). Br J Plast Surg 53, 459, 2000.

4. Jiang, J., Kojima, N., Guo, L., Naruse, K., Makuuchi, M., Miyajima, A., Yan, W., and Sakai, Y. Efficacy of engineered liver tissue based on poly-L-lactic acid scaffolds and fetal mouse liver cells cultured with oncostatin $\mathrm{M}$, nicotinamide, and dimethyl sulfoxide. Tissue Eng 10, 1577, 2004.

5. Ohashi, K., Waugh, J.M., Dake, M.D., Yokoyama, T., Kuge, H., Nakajima, Y., Yamanouchi, M., Naka, H., Yoshioka, A., and Kay, M.A. Liver tissue engineering at extrahepatic sites in mice as a potential new therapy for genetic liver diseases. Hepatology 41, 132, 2005.

6. Salgado, A.J., Coutinho, O.P., and Reis, R.L. Bone tissue engineering: state of the art and future trends. Macromol Biosci 4, 743, 2004.

7. Deasy, B.M., Li, Y., and Huard, J. Tissue engineering with muscle-derived stem cells. Curr Opin Biotechnol 15, 419, 2004.

8. Patrick, C.W. Breast tissue engineering. Annu Rev Biomed Eng 6, 109, 2004.

9. Dolderer, J.H., Findlay, M.W., Cooper-White, J., Thompson, E.W., Trost, N., Hennessy, O., Penington, A., Morrison, W.A., and Germann, G. In vivo tissue engineering of vascularised adipose tissue for reconstructive surgery: An important step towards human application. Langenbecks Arch Surg 389, 453, 2004.

10. Lundborg, G. Alternatives to autologous nerve grafts. Handchir Mikrochir Plast Chir 36, 1, 2004.

11. Folkman, J., and Hochberg, M. Self-regulation of growth in three dimensions. J Exp Med 138, 745, 1973.

12. Colton, C.K. Implantable biohybrid artificial organs. Cell Transplant 4, 415, 1995.

13. Risau, W. Mechanisms of angiogenesis. Nature 386, 671, 1997.

14. Carmeliet, P. Mechanisms of angiogenesis and arteriogenesis. Nat Med 6, 389, 2000.

15. Patan, S. Vasculogenesis and angiogenesis. Cancer Treat Res 117, 3, 2004.

16. Romanoff, A.L. Membrane growth and function. Ann N Y Acad Sci 155, 288, 1952.

17. Ribatti, D., Nico, B., Vacca, A., Roncali, L., Burri, P.H., and Djonov, V. Chorioallantoic membrane capillary bed: a useful target for studying angiogenesis and anti-angiogenesis in vivo. Anat Rec 264, 317, 2001.

18. Ausprunk, D.H., Knighton, D.R., and Folkman, J. Differentiation of vascular endothelium in the chick chorioallantois: a structural and autoradiographic study. Dev Biol 38, 237, 1974.

19. Kurz, H., Ambrosy, S., Wilting, J., Marme, D., and Christ, B. Proliferation pattern of capillary endothelial cells in chorioallantoic membrane development indicates local growth control, which is counteracted by vascular endothelial growth factor application. Dev Dyn 203, 174, 1995.

20. Yang, E.Y., and Moses, H.L. Transforming growth factor beta 1-induced changes in cell migration, proliferation, and angiogenesis in the chicken chorioallantoic membrane. J Cell Biol 111, 731, 1990.
21. Ausprunk, D.H. Distribution of hyaluronic acid and sulfated glycosaminoglycans during blood-vessel development in the chick chorioallantoic membrane. Am J Anat 177, 313, 1986.

22. Maragoudakis, M.E., Panoutsacopoulou, M., and Sarmonika, M. Rate of basement membrane biosynthesis as an index to angiogenesis. Tissue Cell 20, 531, 1988.

23. Wilting, J., Christ, B., and Bokeloh, M. A modified chorioallantoic membrane (CAM) assay for qualitative and quantitative study of growth factors. Studies on the effects of carriers, PBS, angiogenin, and bFGF. Anat Embryol 183, 259, 1991.

24. Wilting, J., Christ, B., Bokeloh, M., and Weich, H.A. In vivo effects of vascular endothelial growth factor on the chicken chorioallantoic membrane. Cell Tissue Res 274, 163, 1993.

25. Wilting, J., Weich, H.A., and Christ, B. Effects of vascular endothelial growth factor and basic fibroblast growth factor: application with corneal grafts on the chorioallantoic membrane. Acta Anat 147, 207, 1993.

26. Maas, J.W., Groothuis, P.G., Dunselman, G.A., de Goeij, A.F., Struyker Boudier, H.A., and Evers, J.L. Endometrial angiogenesis throughout the human menstrual cycle. Hum Reprod 16, 1557, 2001.

27. Knighton, D., Ausprunk, D., Tapper, D., and Folkman, J. Avascular and vascular phases of tumour growth in the chick embryo. Br J Cancer 35, 347, 1977.

28. Gordon, J.R., and Quigley, J.P. Early spontaneous metastasis in the human epidermoid carcinoma HEp3/chick embryo model: contribution of incidental colonization. Int $\mathbf{J}$ Cancer 38, 437, 1986.

29. Borges, J., Tegtmeier, F.T., Padron, N.T., Mueller, M.C., Lang, E.M., and Stark, G.B. Chorioallantoic membrane angiogenesis model for tissue engineering: a new twist on a classic model. Tissue Eng 9, 441, 2003.

30. Borges, J., Mueller, M.C., Padron, N.T., Tegtmeier, F., Lang, E.M., and Stark, G.B. Engineered adipose tissue supplied by functional microvessels. Tissue Eng 9, 1263, 2003.

31. Algire, G.H. An adaption of the transparent chamber technique to the mouse. J Natl Cancer Inst 4, 1, 1943.

32. Papenfuss, H.D., Gross, J.F., Intaglietta, M., and Treese, F.A. A transparent access chamber for the rat dorsal skin fold. Microvasc Res 18, 311, 1979.

33. Cardon, S.Z., Oestermeyer, C.F., and Bloch, E.H. Effect of oxygen on cyclic red blood cell flow in unanesthetized mammalian striated muscle as determined by microscopy. Microvasc Res 2, 67, 1970.

34. Lehr, H.A., Leunig, M., Menger, M.D., Nolte, D., and Messmer, K. Dorsal skinfold chamber technique for intravital microscopy in nude mice. Am J Pathol 143, 1055, 1993.

35. Leunig, M., Yuan, F., Menger, M.D., Boucher, Y., Goetz, A.E., Messmer, K., and Jain, R.K. Angiogenesis, microvascular architecture, microhemodynamics, and interstitial fluid pressure during early growth of human adenocarcinoma LS174T in SCID mice. Cancer Res 52, 6553, 1992.

36. Endrich, B., Asaishi, K., Gotz, A., and Messmer, K. Technical report-a new chamber technique for microvascular studies in unanesthetized hamsters. Res Exp Med 177, 125, 1980.

37. Menger, M.D., and Lehr, H.A. Scope and perspectives of intravital microscopy-bridge over from in vitro to in vivo. Immunol Today 14, 519, 1993. 
38. Funk, W., Endrich, B., and Messmer, K. A novel method for follow-up studies of the microcirculation in non-malignant tissue implants. Res Exp Med 186, 259, 1986.

39. Menger, M.D., Jaeger, S., Walter, P., Feifel, G., Hammersen, F., and Messmer, K. Angiogenesis and hemodynamics of microvasculature of transplanted islets of Langerhans. Diabetes $\mathbf{3 8}$ Suppl 1, 199, 1989.

40. Vollmar, B., Laschke, M.W., Rohan, R., Koenig, J., and Menger, M.D. In vivo imaging of physiological angiogenesis from immature to preovulatory ovarian follicles. Am J Pathol 159, 1661, 2001.

41. Laschke, M.W., Menger, M.D., and Vollmar, B. Ovariectomy improves neovascularization and microcirculation of freely transplanted ovarian follicles. J Endocrinol 172, 535, 2002.

42. Langer, S., Sinitsina, I., Biberthaler, P., Krombach, F., and Messmer, K. Revascularization of transplanted adipose tissue: a study in the dorsal skinfold chamber of hamsters. Ann Plast Surg 48, 53, 2002.

43. Asaishi, K., Endrich, B., Gotz, A., and Messmer, K. Quantitative analysis of microvascular structure and function in the amelanotic melanoma A-Mel-3. Cancer Res 41, 1898, 1981.

44. Vajkoczy, P., Ullrich, A., and Menger, M.D. Intravital fluorescence videomicroscopy to study tumor angiogenesis and microcirculation. Neoplasia 2, 53, 2000.

45. Menger, M.D., Hammersen, F., Walter, P., and Messmer, K. Neovascularization of prosthetic vascular grafts. Quantitative analysis of angiogenesis and microhemodynamics by means of intravital microscopy. Thorac Cardiovasc Surg 38, 139, 1990.

46. Menger, M.D., Walter, P., Hammersen, F., and Messmer, K. Quantitative analysis of neovascularization of different PTFEimplants. Eur J Cardiothorac Surg 4, 191, 1990.

47. Menger, M.D., Hammersen, F., and Messmer, K. In vivo assessment of neovascularization and incorporation of prosthetic vascular biografts. Thorac Cardiovasc Surg 40, 19, 1992.

48. Kraft, C.N., Hansis, M., Arens, S., Menger, M.D., and Vollmar, B. Striated muscle microvascular response to silver implants: a comparative in vivo study with titanium and stainless steel. J Biomed Mater Res 49, 192, 2000.

49. Kraft, C.N., Burian, B., Perlick, L., Wimmer, M.A., Wallny, T., Schmitt, O., and Diedrich, O. Impact of a nickel-reduced stainless steel implant on striated muscle microcirculation: a comparative in vivo study. J Biomed Mater Res 57, 404, 2001.

50. Kraft, C.N., Weber, W., Burian, B., Zander, D., Wallny, T., Schmitt, O., and Diedrich, O. Striated muscle microvascular response to implants with sol-gel calcium phosphate coating. A comparative in vivo study. Z Orthop Ihre Grenzgeb 140, 672, 2002.

51. Druecke, D., Langer, S., Lamme, E., Pieper, J., Ugarkovic, M., Steinau, H.U., and Homann, H.H. Neovascularization of poly(ether ester) block-copolymer scaffolds in vivo: longterm investigations using intravital fluorescent microscopy. J Biomed Mater Res 68A, 10, 2004.

52. Agrawal, C.M., and Ray, R.B. Biodegradable polymeric scaffolds for musculoskeletal tissue engineering. J Biomed Mater Res 55, 141, 2001.

53. Hodde, J. Naturally occurring scaffolds for soft tissue repair and regeneration. Tissue Eng 8, 295, 2002.

54. Kirkpatrick, C.J., Otto, M., Kooten, T.V., Krump, V., Kriegsmann, J., and Bittinger, F. Endothelial cell cultures as a tool in biomaterial research. J Mater Sci Mater Med 10, 589, 1999.

55. Peters, K., Unger, R.E., Barth, S., Gerdes, T., and Kirkpatrick, C.J. Induction of apoptosis in human microvascular endothelial cells by divalent cobalt ions. Evidence for integrinmediated signaling via the cytoskeleton. J Mater Sci Mater Med 12, 955, 2001.

56. Kirkpatrick, C.J., Unger, R.E., Krump-Konvalinkova, V., Peters, K., Schmidt, H., and Kamp, G. Experimental approaches to study vascularization in tissue engineering and biomaterial applications. J Mater Sci Mater Med 14, 677, 2003.

57. Peters, K., Schmidt, H., Unger, R.E., Otto, M., Kamp, G., and Kirkpatrick, C.J. Software-supported image quantification of angiogenesis in an in vitro culture system: application to studies of biocompatibility. Biomaterials 23, 3413, 2002.

58. Black, A.F., Hudon, V., Damour, O., Germain, L., and Auger, F.A. A novel approach for studying angiogenesis: a human skin equivalent with a capillary-like network. Cell Biol Toxicol 15, 81, 1999.

59. Frerich, B., Lindemann, N., Kurtz-Hoffmann, J., and Oertel, $\mathrm{K}$. In vitro model of a vascular stroma for the engineering of vascularized tissues. Int J Oral Maxillofac Surg 30, 414, 2001.

60. Pinney, E., Liu, K., Sheeman, B., and Mansbridge, J. Human three-dimensional fibroblast cultures express angiogenic activity. J Cell Physiol 183, 74, 2000.

61. Vogel, V., and Baneyx, G. The tissue engineering puzzle: a molecular perspective. Annu Rev Biomed Eng 5, 441, 2003.

62. Hodde, J.P., Record, R.D., Liang, H.A., and Badylak, S.F. Vascular endothelial growth factor in porcine-derived extracellular matrix. Endothelium 8, 11, 2001.

63. Meinert, M., Eriksen, G.V., Petersen, A.C., Helmig, R.B., Laurent, C., Uldbjerg, N., and Malmstrom, A. Proteoglycans and hyaluronan in human fetal membranes. Am J Obstet Gynecol 184, 679, 2001.

64. McPherson, T.B., and Badylak, S.F. Characterization of fibronectin derived from porcine small intestinal submucosa. Tissue Eng 4, 75, 1998.

65. Chaplin, J.M., Costantino, P.D., Wolpoe, M.E., Bederson, J.B., Griffey, E.S., and Zhang, W.X. Use of an acellular dermal allograft for dural replacement: an experimental study. Neurosurgery 45, 320, 1999.

66. Pieper, J.S., van Wachem, P.B., van Luyn, M.J.A., Brouwer, L.A., Hafmans, T., Veerkamp, J.H., and van Kuppevelt, T.H. Attachment of glycosaminoglycans to collagenous matrices modulates the tissue response in rats. Biomaterials 21, 1689, 2000.

67. Anderson, C.R., Ponce, A.M., and Price, R.J. Immunohistochemical identification of an extracellular matrix scaffold that microguides capillary sprouting in vivo. J Histochem Cytochem 52, 1063, 2004.

68. Badylak, S.F. The extracellular matrix as a scaffold for tissue reconstruction. Semin Cell Dev Biol 13, 377, 2002.

69. Norrby, K. Angiogenesis: new aspects relating to its initiation and control. APMIS 105, 417, 1997.

70. Yancopoulos, G.D., Davis, S., Gale, N.W., Rudge, J.S., Wiegand, S.J., and Holash, J. Vascular-specific growth factors and blood vessel formation. Nature 407, 242, 2000.

71. Pandit, A.S., Feldman, D.S., Caulfield, J., and Thompson, A. Stimulation of angiogenesis by FGF-1 delivered through a modified fibrin scaffold. Growth Factors 15, 113, 1998. 
72. Pandit, A.S., Feldman, D.S., and Caulfield, J. In vivo wound healing response to a modified degradable fibrin scaffold. J Biomater Appl 12, 222, 1998.

73. Shea, L.D., Smiley, E., Bonadio, J., and Mooney, D.J. DNA delivery from polymer matrices for tissue engineering. Nat Biotechnol 17, 551, 1999.

74. Tabata, Y., Miyao, M., Yamamoto, M., and Ikada, Y. Vascularization into a porous sponge by sustained release of basic fibroblast growth factor. J Biomater Sci Polym Ed 10, 957, 1999.

75. Perets, A., Baruch, Y., Weisbuch, F., Shoshany, G., Neufeld, G., and Cohen, S. Enhancing the vascularization of threedimensional porous alginate scaffolds by incorporating controlled release basic fibroblast growth factor microspheres. J Biomed Mater Res 65A, 489, 2003.

76. Richardson, T.P., Peters, M.C., Ennett, A.B., and Mooney, D.J. Polymeric system for dual growth factor delivery. Nat Biotechnol 19, 1029, 2001.

77. Masuda, T., Furue, M., and Matsuda, T. Novel strategy for soft tissue augmentation based on transplantation of fragmented omentum and preadipocytes. Tissue Eng 10, 1672, 2004.

78. Riabikhin, A.W., Walgenbach, K.J., Martiny-Baron, G., Bittner, K., Bannasch, H., Seifer, B., Marme, D., and Stark, G.B. Increased three-dimensional endothelial growth in a collagen matrix following addition of recombinant VEGF and liposomal gene transfer with VEGF-165. Cells Tissues Organs 166, 16, 2000.

79. Bonadio, J., Smiley, E., Patil, P., and Goldstein, S. Localized, direct plasmid gene delivery in vivo: prolonged therapy results in reproducible tissue regeneration. Nat Med 5, 753, 1999.

80. Schwarz, E.R., Speakman, M.T., Patterson, M., Hale, S.S., Isner, J.M., Kedes, L.H., and Kloner, R.A. Evaluation of the effects of intramyocardial injection of DNA expressing vascular endothelial growth factor (VEGF) in a myocardial infarction model in the rat - angiogenesis and angioma formation. J Am Coll Cardiol 35, 1323, 2000.

81. Taniyama, Y., Morishita, R., Hiraoka, K., Aoki, M., Nakagami, H., Yamasaki, K., Matsumoto, K., Nakamura, T., Kaneda, Y., and Ogihara, T. Therapeutic angiogenesis induced by human hepatocyte growth factor gene in rat diabetic hind limb ischemia model: molecular mechanisms of delayed angiogenesis in diabetes. Circulation 104, 2344, 2001.

82. Kasahara, H., Tanaka, E., Fukuyama, N., Sato, E., Sakamoto, H., Tabata, Y., Ando, K., Iseki, H., Shinozaki, Y., Kimura, K., Kuwabara, E., Koide, S., Nakazawa, H., and Mori, H. Biodegradable gelatin hydrogel potentiates the angiogenic effect of fibroblast growth factor 4 plasmid in rabbit hindlimb ischemia. J Am Coll Cardiol 41, 1056, 2003.

83. Simons, M., Bonow, R.O., Chronos, N.A., Cohen, D.J., Giordano, F.J., Hammond, H.K., Laham, R.J., Li, W., Pike, M., Sellke, F.W., Stegmann, T.J., Udelson, J.E., and Rosengart, T.K. Clinical trials in coronary angiogenesis: issues, problems, consensus: an expert panel summary. Circulation 102, E73, 2000

84. Holder, W.D., Jr., Gruber, H.E., Roland, W.D., Moore, A.L., Culberson, C.R., Loebsack, A.B., Burg, K.J.L., and Mooney, D.J. Increased vascularization and heterogeneity of vascular structures occurring in polyglycolide matrices containing aortic endothelial cells implanted in the rat. Tissue Eng 3, 149, 1997.

85. Mooney, D.J., and Mikos, A.G. Growing new organs. Sci Am 280, 60, 1999.

86. Burg, K.J., Holder, W.D. Jr., Culberson, C.R., Beiler, R.J., Greene, K.G., Loebsack, A.B., Roland, W.D., Eiselt, P., Mooney, D.J., and Halberstadt, C.R. Comparative study of seeding methods for three-dimensional polymeric scaffolds. J Biomed Mater Res 51, 642, 2000.

87. Kaigler, D., Krebsbach, P.H., West, E.R., Horger, K., Huang, Y.C., and Mooney, D.J. Endothelial cell modulation of bone marrow stromal cell osteogenic potential. FASEB J 19, 665, 2005.

88. Wendt, D., Marsano, A., Jakob, M., Heberer, M., and Martin, I. Oscillating perfusion of cell suspensions through threedimensional scaffolds enhances cell seeding efficiency and uniformity. Biotechnol Bioeng 84, 205, 2003.

89. Tremblay, P.L., Hudon, V., Berthod, F., Germain, L., and Auger, F.A. Inosculation of tissue-engineered capillaries with the host's vasculature in a reconstructed skin transplanted on mice. Am J Transplant 5, 1002, 2005.

90. Cho, S.W., Lim, S.H., Kim, I.K., Hong, Y.S., Kim, S.S., Yoo, K.J., Park, H.Y., Jang, Y., Chang, B.C., Choi, C.Y., Hwang, K.C., and Kim, B.S. Small-diameter blood vessels engineered with bone marrow-derived cells. Ann Surg 241, 506, 2005.

91. Hibino, N., Shin'oka, T., Matsumura, G., Ikada, Y., and Kurosawa, $\mathrm{H}$. The tissue-engineered vascular graft using bone marrow without culture. J Thorac Cardiovasc Surg 129, 1064, 2005.

92. Kaushal, S., Amiel, G.E., Guleserian, K.J., Shapira, O.M., Perry, T., Sutherland, F.W., Rabkin, E., Moran, A.M., Schoen, F.J., Atala, A., Soker, S., Bischoff, J., and Mayer, J.E., Jr. Functional small-diameter neovessels created using endothelial progenitor cells expanded ex vivo. Nat Med 7, 1035, 2001.

93. Yamashita, J., Itoh, H., Hirashima, M., Ogawa, M., Nishikawa, S., Yurugi, T., Naito, M., Nakao, K., and Nishikawa, S. Flk1-positive cells derived from embryonic stem cells serve as vascular progenitors. Nature 408, 92, 2002.

94. Asahara, T., and Kawamoto, A. Endothelial progenitor cells for postnatal vasculogenesis. Am J Physiol Cell Physiol 287, C572, 2004.

95. Zwaginga, J.J., and Doevendans, P. Stem cell-derived angiogenic/vasculogenic cells: possible therapies for tissue repair and tissue engineering. Clin Exp Pharmacol Physiol 30, 900, 2003.

96. Erol, O.O., and Spira, M. New capillary bed formation with a surgically constructed arteriovenous fistula. Surg Forum 30, 530, 1979.

97. Hirase, Y., Valauri, F.A., and Buncke, H.J. Creation of neovascularised free flaps using vein grafts as pedicles: a preliminary report on experimental models. Br J Plast Surg 42, 216, 1989.

98. Takato, T., Zuker, R.M., and Turley, C.B. Prefabrication of skin flaps using vein grafts: an experimental study in rabbits. Br J Plast Surg 44, 593, 1991.

99. Wilson, Y.T., Kumta, S., Hickey, M.J., Hurley, J.V., and Morrison, W.A. Use of free interpositional vein grafts as pedicles for prefabrication of skin flaps. Microsurgery 15, 717, 1994. 
100. Mian, R., Morrison, W.A., Hurley, J.V., Penington, A.J., Romeo, R., Tanaka, Y., and Knight, K.R. Formation of new tissue from an arteriovenous loop in the absence of added extracellular matrix. Tissue Eng 6, 595, 2000.

101. Mian, R.A., Knight, K.R., Penington, A.J., Hurley, J.V., Messina, A., Romeo, R., and Morrison, W.A. Stimulating effect of an arteriovenous shunt on the in vivo growth of isografted fibroblasts: a preliminary report. Tissue Eng 7, 73, 2001.
Address reprint requests to:

Matthias W. Laschke, M.D.

Institute for Clinical and Experimental Surgery

University of Saarland

D-66421 Homburg/Saar

Germany

E-mail: matthias.laschke@uniklinik-saarland.de 